\title{
CLINICAL AND HAEMATOLOGICAL EVALUATION OF LEUKAEMIAS, USING CYTOCHEMICAL STAINS AND IMMUNOPHENOTYPING
}

\author{
Abu Arshad Abdul Salaam¹, Senthil Kumar Mani²
}

${ }_{1}^{1}$ Assistant Professor, Department of Pathology, Government Mohan Kumara Mangalam Medical College, Salem, Tamilnadu, India. ${ }^{2}$ Associate Professor, Department of Pathology, Thanjavur Medical College, Thanjavur, Tamilnadu, India.

ABSTRACT
BACKGROUND
Leukaemias are characterised by abnormal proliferation of haematopoietic cells, causing progressive infiltration of the marrow. It
is the eleventh most common cancer in the world, and increasingly found now. Two widely used classifications are currently used,
the FAB, and the WHO classification, which has got supplanted now, with increasing knowledge on cytomorphology and
cytogenetics. This study attempts to evaluate the role of cytochemistry in various types of leukaemias, as well as the role of
immunophenotyping in a select few cases, which were referred to the Department of Pathology, at Thanjavur Medical College. We
wanted to study, the types and subtypes of leukaemias using cytochemistry, their morphology, the demographic distribution and
their clinical and haematological presentation.

\section{METHODS}

The present study had a sample size of 56 cases of leukaemia, diagnosed in the department of pathology, Thanjavur Medical College. Those cases referred to the Department of pathology, with clinical suspicion, were subjected to peripheral smear study by standard Romanowsky stains first, mainly by Leishman's stain and a presumptive diagnosis was made. Following which peripheral blood smears were subjected to special cytochemical stains using Sudan Black B (SBB) and Periodic Acid Schiff's reagent stain (PAS). The percentage of blast cells were enumerated, and the cytomorphology studied based on their positive staining effects on the respective blood smears. Thereby, the types and subtypes of leukaemias were classified and reported as per FAB classification. Relevant clinical history was obtained from each case, with parameters relating to splenomegaly, hepatomegaly, and lymphadenopathy. Haematological investigations were done on a three-part automated cell counter, and values pertaining to haemoglobin, total count, and platelet count were also noted. Clinical and haematological correlation was thus made with the diagnosed cases, and statistical analysis was undertaken. In six cases, immunophenotyping using flow cytometry, and standard panel markers, was undertaken; when in doubt, its concordance patterns were also noted.

\section{RESULTS}

56 cases of leukaemia, identified by morphology and cytochemistry, were seen in the study between January 2015 and June 2015. Cytochemical stains used were Sudan black B, and PAS. Out of the total, 36 cases were acute, rest were chronic cases. AML accounted for $43 \%$ of the cases, followed by CML at 33\%, and ALL at $22 \%$. A slight female preponderance was seen in the number of AML cases, but a male predominance was seen in ALL. ALL was common in the child age group, followed by AML, and CML in the 21-40 age group, followed by AML. CLL was seen mostly above 40 yrs. of age. Anaemia was more in acute leukaemias especially ALL, followed by AML. Total count values were high in CML, followed by AML. Platelet counts were less in acute leukaemias, especially ALL, followed by AML. Splenomegaly was the commonest feature seen in 21 cases. Immunophenotyping was done in 6 cases, 4 cases were concordant, showing a $67 \%$ rate.

\section{CONCLUSIONS}

In a setting where there is a lack of facilities for flow cytometry, as in majority of centres in the developing countries, morphology combined with cytochemistry, still serves as the best means in diagnosing leukaemia cases.

HOW TO CITE THIS ARTICLE: Salaam AAA, Mani SK. Clinical and haematological evaluation of leukaemias, using cytochemical stains and immunophenotyping. J. Evolution Med. Dent. Sci. 2019;8(19):1572-1577, DOI: 10.14260/jemds/2019/348

\section{BACKGROUND}

Leukaemias are characterised by neoplastic proliferation of haematopoietic cells, which form a major proportion of haematopoietic neoplasms, which are diagnosed worldwide. ${ }^{1}$

Leukaemias are classified into two broad groups, myeloid and lymphoid, based on the origin of the leukemic stem cell clone. They cause progressive infiltration of the bone marrow and in certain forms the lymphatic tissues are particularly

'Financial or Other Competing Interest': None.

Submission 18-03-2019, Peer Review 23-04-2019,

Acceptance 30-04-2019, Published 13-05-2019.

Corresponding Author:

Dr.Senthil Kumar Mani,

Associate Professor, Department of Pathology,

Thanjavur Medical College,

Thanjavur-613004, Tamilnadu, India.

E-mail: senthilpatterson@gmail.com,masekumarpath@gmail.com DOI: $10.14260 /$ jemds $/ 2019 / 348$

\section{(c) $(1) \ominus$}

affected. Leukaemia is the ninth commonest cancer in the world, and is the ninth most common in males, which is $3 \%$ of total cancers in them, and is eleventh most common in females, $2 \%$ of total cancers in them.

Age standardized rates for Asian males range from 6.3 to 10.6 per 100,000 . In India the number of new cases were 13 per 100, 000 men and women per year. Generally males are affected more than females. ${ }^{1,2,3}$ Two widely used classifications are used, one by the French, American, and British group called the FAB Classification, and other by the World Health Organisation (WHO Classification), based on the morphologic findings, genetic abnormalities, clinical and Immunophenotyping characteristics. ${ }^{3,2,5}$ Overall annual incidence in the general population is 4 per 100,000 , with approximately $70 \%$ being Acute myeloid leukaemia (AML). AML accounts for about $90 \%$ of the acute leukaemias in adult population and $15 \%$ of the cases in childhood leukaemias. Acute lymphoblastic leukaemia (ALL) is primarily a 
childhood disease and commonly seen at a peak age of 2 or 3 years. Chronic myeloid leukaemia (CML) occurs typically between ages 40 and 60, and the Chronic lymphoid leukaemia (CLL) occur most after 65 years of age. This study attempts to evaluate the role of cytochemistry in classifying the various types of Leukaemia and its subtypes, by a combination of morphology on the peripheral blood smear, as well as correlate with the clinical and haematological findings of the cases, with available means in our laboratory. Cytomorphological assessment, based on FAB Classification was made, Immunophenotyping, was done for a select few cases, where there was doubt, or ambiguity, and its concordance with the cytochemical staining patterns and findings were taken into account.1, 6, 4, 7 Peripheral blood smear, suspected of leukaemia, in cases received at the Department of pathology, Thanjavur Medical College, was taken during the period from January 2015 to June 2016, and studied for this purpose. The study also aims to tell that the simple and cost-effective method of cytochemical stains, are a valuable tool, in aiding the diagnostic methods in leukaemia.

\section{Aims and Objectives}

1. To classify leukaemias and subtype acute leukaemias with the help of cytochemistry according to French American British (FAB) Classification.

2. To study the cytomorphology of the various types of leukaemias.

3. To study the clinical and haematological manifestations of the various types of leukaemias.

4. To study the demographic data (Age and Sex) distribution in the various types of leukaemias.

\section{METHODS}

\section{Study Design}

Observational study.

The present study had a sample size of 56 cases of leukaemia, diagnosed in the department of pathology, Thanjavur medical college. Sample size was taken based on the convenience of study. Those cases referred to the department of pathology, with clinical suspicion, were subjected to peripheral smear study by standard Romanowsky stains first, mainly by Leishman's stain and a presumptive diagnosis was made. Following which peripheral blood smears were subjected to special cytochemical stains using Sudan Black B (SBB) and Periodic acid Schiff's reagent stain(PAS).7,8,9,10,11 The percentage of blast cells were enumerated, and the cytomorphology studied based on their positive staining effects on the respective blood smears, were noted. Thereby the types and subtypes of leukaemias were classified and reported as per FAB Classification. ${ }^{1,4,3}$

\section{Inclusion Criteria}

Peripheral blood smear from all cases of all age groups who presented with clinical features and abnormal haematological values suggestive of leukaemia.

\section{Exclusion Criteria}

Nil.

\section{Statistical Analysis}

The collected data was entered in Microsoft excel, and analysed using statistical package for social sciences (SPSS
18.0) software. One-way ANOVA was used to test the significance of clinico-haematological parameters.

\section{RESULTS}

The present study comprised of 56 cases of suspected Leukaemia, taken from the department of pathology, Thanjavur Medical College, between January 2015 and June 2016. The observations and the results deduced were as follows.

\begin{tabular}{|c|c|c|}
\hline Age in Years & No. of Cases & $\mathbf{\%}$ \\
\hline$\leq 10$ & 10 & 18 \\
\hline $11-20$. & 12 & 21 \\
\hline $21-30$ & 7 & 12 \\
\hline $31-40$ & 12 & 21 \\
\hline $41-50$ & 8 & 14 \\
\hline $51-60$ & 2 & 4 \\
\hline $61-70$ & 2 & 4 \\
\hline $71-80$ & 2 & 4 \\
\hline$>81$ & 1 & 2 \\
\hline Total & $\mathbf{5 6}$ & \\
\hline \multicolumn{2}{|c|}{ Table 1. Age Distribution of Patients } \\
\hline
\end{tabular}

The cases were in the range of 1 to 93 years. Table. 1 , shows the age distribution, with the majority of the percentage lying in the age group 11 to 20 years, and 31 to 40 years, each having 12 cases in the category, which was found to be $21 \%$. This was followed by the age group less than 10 years, with 10 cases, which was $18 \%$, and 41 to 50 years group with 8 cases having 14\%, closely followed by the 21 to 30 years group, with 7 cases, amounting to $12 \%$.

\begin{tabular}{|c|c|c|c|c|c|c|c|c|}
\hline \multirow{2}{*}{ Sex } & \multicolumn{2}{|c|}{ ALL } & \multicolumn{2}{c|}{ AML } & \multicolumn{2}{c|}{ CML } & \multicolumn{2}{c|}{ CLL } \\
\cline { 2 - 9 } & Nos. & $\%$ & Nos. & $\%$ & Nos. & \% & Nos. & $\%$ \\
\hline Male & 8 & $67 \%$ & 10 & $42 \%$ & 8 & $47 \%$ & 1 & $33 \%$ \\
\hline Female & 4 & $33 \%$ & 14 & $58 \%$ & 9 & $53 \%$ & 2 & $67 \%$ \\
\hline
\end{tabular}

Table 2. Sex Distribution of Cases

Total Male Cases - 27 - 48\%. Total Female Cases - $29-52 \%$

The total Male cases in AML, was 10 in number, and Females were 14 , accounting to $42 \%$ and $58 \%$ respectively. The total Male cases in ALL, were 8, and females were 4, with a $67 \%$ and $33 \%$ respectively.

\begin{tabular}{|c|c|c|}
\hline $\begin{array}{c}\text { Types and Subtypes of } \\
\text { Leukaemia }\end{array}$ & $\begin{array}{c}\text { No. of Cases and } \\
\text { Percentage (\%) }\end{array}$ \\
\hline AML (n=24) & No. of Cases & Percentage (\%) \\
\hline M0 & 2 & 8 \\
\hline M1 & 6 & 25 \\
\hline M2 & 13 & 55 \\
\hline M3 & 1 & 4 \\
\hline M4 & 0 & 8 \\
\hline M5 M6 M7 & 6 & 0 \\
\hline \multicolumn{3}{|c|}{ ALL (n= 12) } \\
\hline L1 & 6 & 50 \\
\hline L2 & 0 & 0 \\
\hline L3 & 9 & 52 \\
\hline Chronic phase & 3 & 18 \\
\hline Accelerated phase & 3 & 18 \\
\hline Blast crisis &
\end{tabular}




\begin{tabular}{|c|c|c|}
\hline $\begin{array}{c}\text { Chronic Neutrophilic } \\
\text { leukaemia (CNL) }\end{array}$ & 1 & 6 \\
\hline Juvenile CML & 1 & 6 \\
\hline CLL (n=3) & 3 & 100 \\
\hline Table 3. Distribution of Patients According to Types and \\
Sub-Types of Leukaemia \\
\hline
\end{tabular}

This table depicts the distributive nature of the different types and subtypes of leukaemia. Of the total 56 cases, AML, with 24 cases (43\%), was the highest, followed by CML with 17 cases (30\%), ALL with 12 cases (22\%) and CLL with 3 cases (5\%), was the least. In AML, 13 cases were of M2 (55\%), followed by M1, which had 6 cases (25\%). In ALL, 6 cases were seen, each in L1 and L2, 50\% equally distributed. CML, had 9 cases (52\%) in the chronic phase, which was highest, with 3 each in accelerated phase (18\%) and blast crisis (18\%). One case of Juvenile CML, and another case of $\mathrm{CNL}$, was also seen.

\begin{tabular}{|c|c|c|c|c|c|c|c|c|}
\hline \multirow{2}{*}{$\begin{array}{c}\text { Hb in } \\
\text { Gram \% }\end{array}$} & \multicolumn{2}{|c|}{ ALL } & \multicolumn{2}{c|}{ AML } & \multicolumn{2}{c|}{ CML } & \multicolumn{2}{c|}{ CLL } \\
\cline { 2 - 9 } & Nos. & $\mathbf{\%}$ & Nos. & \% & Nos. & \% & Nos. & \% \\
\hline$<6$ & 10 & $83 \%$ & 17 & $71 \%$ & 6 & $35 \%$ & 1 & $34 \%$ \\
\hline $6.1-9$ & 1 & $9 \%$ & 6 & $25 \%$ & 6 & $35 \%$ & 1 & $33 \%$ \\
\hline $9.1-12$ & 1 & $8 \%$ & 1 & $4 \%$ & 4 & $24 \%$ & 1 & $33 \%$ \\
\hline 12 and above & 0 & $0 \%$ & 0 & $0 \%$ & 1 & $6 \%$ & 0 & $0 \%$ \\
\hline
\end{tabular}

Table 4. Haemoglobin Distribution Among the Cases

Haemoglobin was seen to be less, and anaemia more prevalent in acute leukaemias than the chronic ones. ALL had as high as $83 \%$ cases with below $6 \mathrm{gm} / \mathrm{dl}$ values, followed by AML which had 71\% cases. CML and CLL had 35\% and 34\% respectively.

\begin{tabular}{|c|c|c|c|c|c|c|c|c|}
\hline \multirow{2}{*}{ TLC } & $\begin{array}{c}\text { ALL } \\
(\mathbf{n = 1 2})\end{array}$ & \multicolumn{2}{c|}{$\begin{array}{c}\text { AML } \\
(\mathbf{n = 2 4 )}\end{array}$} & $\begin{array}{c}\text { CML } \\
(\mathbf{n = 1 7})\end{array}$ & $\begin{array}{c}\text { CLL } \\
(\mathbf{n = 3})\end{array}$ \\
\cline { 2 - 9 } & Nos. & $\%$ & Nos. & $\%$ & Nos. & $\%$ & Nos. & $\%$ \\
\hline$<4000$ & 3 & $25 \%$ & 0 & $0 \%$ & 0 & $0 \%$ & 1 & $33 \%$ \\
\hline $4001-11000$ & 0 & $0 \%$ & 3 & $12 \%$ & 0 & $0 \%$ & 2 & $67 \%$ \\
\hline $11001-50000$ & 4 & $33 \%$ & 11 & $46 \%$ & 3 & $18 \%$ & 0 & $0 \%$ \\
\hline $50001-100000$ & 3 & $25 \%$ & 6 & $25 \%$ & 4 & $24 \%$ & 0 & $0 \%$ \\
\hline $100001-200000$ & 2 & $17 \%$ & 4 & $17 \%$ & 5 & $29 \%$ & 0 & $0 \%$ \\
\hline$>200000$ & 0 & $0 \%$ & 0 & $0 \%$ & 5 & $29 \%$ & 0 & $0 \%$ \\
\hline & \multicolumn{10}{|c|}{ Table 5. Total Leukocyte Count in Cases } \\
\hline
\end{tabular}

The total leukocyte count showed higher values of up to $50,000 / \mu \mathrm{l}$, in $46 \%$ of AML cases, and up to $100,000 / \mu \mathrm{l}$ in $25 \%$ of them. ALL showed $33 \%$ and $25 \%$ in the same value range. Both AML and ALL, had 33\% cases with a total count value up to $200,000 / \mu \mathrm{l}$. CML, had $29 \%$ cases of total count values, up to and with more than $200,000 / \mu \mathrm{l}$. CLL, by and large had a normal range of total count value between 4000 to $11,000 / \mu \mathrm{l}$ in $67 \%$ of the cases. $33 \%$ of CLL, and $25 \%$ of ALL, had a total count value less than $4000 / \mu$ l.

\begin{tabular}{|c|c|c|c|c|c|c|c|c|}
\hline \multirow{2}{*}{$\begin{array}{c}\text { Platelet } \\
\text { Count } \\
\text { / cu mm }\end{array}$} & \multicolumn{2}{|c|}{$\begin{array}{c}\text { ALL } \\
(n=12)\end{array}$} & \multicolumn{2}{|c|}{$\begin{array}{c}\text { AML } \\
(n=24)\end{array}$} & \multicolumn{2}{|c|}{$\begin{array}{c}\text { CML } \\
(n=17)\end{array}$} & \multicolumn{2}{|c|}{$\begin{array}{c}\text { CLL } \\
(n=3)\end{array}$} \\
\hline & Nos. & $\%$ & Nos. & $\%$ & Nos. & $\%$ & Nos. & $\%$ \\
\hline$<50000$ & 9 & $75 \%$ & 17 & $71 \%$ & 4 & $24 \%$ & 0 & $0 \%$ \\
\hline 50000 - 1 lac & 1 & $8 \%$ & 2 & $8 \%$ & 0 & $0 \%$ & 1 & $34 \%$ \\
\hline Lac - 1.5 Lacs & 0 & $0 \%$ & 1 & $4 \%$ & 0 & $0 \%$ & 1 & $33 \%$ \\
\hline$>1.5$ Lacs & 2 & $17 \%$ & 4 & $17 \%$ & 13 & $76 \%$ & 1 & $33 \%$ \\
\hline & & & & & & & & \\
\hline
\end{tabular}

Platelet counts were seen less than 50,000/cumm, in $75 \%$ of AML, and in $71 \%$ of ALL cases. CML, had $76 \%$ cases, with more than 100,000 /cumm, whereas $24 \%$ had less than $50,000 /$ cumm. CLL had $34 \%$ cases, up to the value of $100.000 /$ cumm, and more than $150,000 /$ cumm in $33 \%$ cases.

\begin{tabular}{|c|c|c|c|c|}
\hline $\begin{array}{c}\text { Para- } \\
\text { meters }\end{array}$ & $\begin{array}{c}\text { AML } \\
(n=24)\end{array}$ & $\begin{array}{c}\text { ALL } \\
(n=12)\end{array}$ & $\begin{array}{c}\text { CML } \\
(n=17)\end{array}$ & $\begin{array}{c}\text { CLL } \\
(n=3)\end{array}$ \\
\hline \begin{tabular}{|c|} 
Mean \\
SD: Hb \\
(gm/dl)
\end{tabular} & $\begin{array}{l}5.533 \pm \\
2.77\end{array}$ & $\begin{array}{c}4.975 \pm \\
1.24\end{array}$ & $\begin{array}{c}6.724 \pm \\
1.68\end{array}$ & $\begin{array}{l}8.601 \pm \\
2.150\end{array}$ \\
\hline \begin{tabular}{|c|} 
Mean \\
SD: TLC \\
$($ per $\mu l)$
\end{tabular} & $\begin{array}{c}56166.667 \pm \\
52432.25\end{array}$ & $\begin{array}{l}72343.166 \pm \\
70265.325\end{array}$ & $\begin{array}{c}106258.824 \pm \\
82563.265\end{array}$ & $\begin{array}{c}31900 \pm \\
28564.325\end{array}$ \\
\hline \begin{tabular}{|c|} 
Mean \\
SD: \\
Platelet \\
Count \\
(/cmm)
\end{tabular} & $\begin{array}{c}55625.012 \pm \\
58268.635\end{array}$ & $\begin{array}{c}68916.011 \pm \\
34865.854\end{array}$ & $\mid \begin{array}{c}226647.059 \pm \\
123562\end{array}$ & $\begin{array}{c}162666.66 \pm \\
143652.21\end{array}$ \\
\hline \multicolumn{5}{|c|}{$\begin{array}{c}\text { Table 7. Different Haematological Parameters } \\
\text { According to The Types of Leukaemia }\end{array}$} \\
\hline
\end{tabular}

Table 7 provides the different statistics for the haematological parameters according the types of leukaemia. The maximum mean haemoglobin level was observed in CLL, followed by CML, AML and ALL, the least. The mean Total count, was maximum in CML, followed by ALL, AML and CLL. The mean platelet count, was high in CML, followed by CLL, ALL, and least in AML. Using One-way ANOVA, by SPSS, the significance analysis of the differences in the group means, resulted into a $\mathrm{p}$ value of $<0.0001$, and indicated, it was highly significant across the leukaemia types.

\begin{tabular}{|c|c|c|c|}
\hline Signs & $\begin{array}{c}\text { Hb } \\
(\mathrm{gm} / \mathrm{dl})\end{array}$ & $\begin{array}{l}\text { TLC } \\
(/ \text { ul })\end{array}$ & $\begin{array}{c}\text { Platelet Count } \\
\text { (Lacs/cmm) }\end{array}$ \\
\hline $\begin{array}{l}\text { Lymphadenopathy } \\
(\mathrm{n}=7)\end{array}$ & $\begin{array}{c}6.36 \pm \\
0.43\end{array}$ & $\begin{array}{c}69246.799 \pm \\
33672.368\end{array}$ & $\begin{array}{c}130200.565 \pm \\
8349.952\end{array}$ \\
\hline $\begin{array}{l}\text { Hepatomegaly } \\
(\mathrm{n}=16)\end{array}$ & $\begin{array}{c}6.03 \pm \\
1.23\end{array}$ & $\begin{array}{c}63226.735 \pm \\
30276.269\end{array}$ & \begin{tabular}{|c|}
$108775.755 \pm$ \\
51687.363
\end{tabular} \\
\hline $\begin{array}{l}\text { Splenomegaly } \\
(\mathrm{n}=21)\end{array}$ & $\begin{array}{c}4.88 \pm \\
2.14\end{array}$ & $\begin{array}{c}47874.394 \pm \\
2163.351\end{array}$ & $\begin{array}{c}103181.282 \pm \\
32269.779\end{array}$ \\
\hline p-Value & 0.52 & 0.54 & 0.51 \\
\hline \multicolumn{4}{|c|}{$\begin{array}{c}\text { Table 8. Comparison of Clinical Features with Reference to } \\
\text { Haematological Values }\end{array}$} \\
\hline
\end{tabular}

With regards to haemoglobin, the highest mean levels were seen with cases having lymphadenopathy, and the lowest in cases with splenomegaly. The difference in mean $\mathrm{Hb}$ levels by one-way ANOVA, resulted in a p value of 0.52 . In the 
case of total count, the highest value was observed in patients with splenomegaly, and the least was seen in cases with hepatomegaly, the $\mathrm{p}$ value obtained, was 0.54 . And with platelet count, the highest mean values obtained were in patients with lymphadenopathy, followed by hepatomegaly and the least in splenomegaly. The $p$ value obtained here was 0.51 . There were no statistically significant differences, between the group means, and the clinical features, as determined by one-way ANOVA.

Distribution of acute cases of leukaemia as per cytochemistry. Out of 56 cases in total, 36 cases were acute, AML was 24 , which was $67 \%$, and ALL was 12 , at $33 \%$, for the cytochemical staining with both SBB, and PAS.

\begin{tabular}{|c|c|c|}
\hline Cytochemistry & AML & ALL \\
\hline SBB+, PAS- & $24(67 \%)$ & 0 \\
\hline SBB -, PAS + & 0 & $12(33 \%)$ \\
\hline Total & $\mathbf{2 4}$ & $\mathbf{1 2}$ \\
\hline
\end{tabular}

\section{Immunophenotyping Results}

6 cases underwent flow cytometry, using peripheral blood samples, with 2 cases using regular AML panel and 3 cases with ALL panel, and with one CML case with its panel, for cases suspected and doubtful. Though they showed cytochemical stain positive, the results were obtained, with the plots on the side scatter graph. 4 cases were concordant with the cytochemical stained smear diagnosis. But 2 cases of ALL, were partially concordant, and were requiring bone marrow aspirate samples for flow cytometry. Flow concordance percentage was $67 \%$, and the remaining $33 \%$ was not in concordance, for peripheral blood sample-

1. AML M2 showed CD 13, CD, 33, CD, 117 positivity

2. AML M1 showed CD 13, CD 33 positivity

3. ALL L1 showed CALLA positivity with CD10 gated blasts.

4. ALL L2 showed mild blasts but required a bone marrow aspirate analysis.

5. CML showed CD117, CD13, CD33, CD34 positivity in the gated blasts.

6. ALL L1 showed lymphocytosis, required a bone marrow aspirate analysis.

\section{DISCUSSION}

Leukaemias, as such are now common, and affects all ages and genders. It requires a multi-parameter approach for its diagnosis, which includes cytomorphology study, with phenotypic and genotypic studies. In the present study 56 cases, were evaluated, by studying their morphology using cytochemical stains, as well as clinical features, and with 6 cases for concordant Immunophenotyping, using lineage specific panels with markers.1,12,13,14,15 of the 56 cases, 36 cases were acute leukaemias (64\%), of which 24 were AML (43\%), and 12 were ALL (22\%). The rest 20 cases were chronic cases (36\%), of which 17 were CML (30\%), which include one case of chronic neutrophilic leukaemia, and 3 were CLL cases (5\%). This clearly shows acute leukaemias, being more common than chronic ones. In the acute group, AML was more common than ALL, and in the chronic group CML was commoner than CLL. After subtyping of acute leukaemias with cytochemistry, the study showed in AML, 2 cases of M0 (8\%), 6 cases of M1 (25\%), 13 cases of M2 (55\%), 1 case of M3 (4\%), 2 cases of M4 (8\%). No cases of M5, M6 and M7 were detected. This showed that AML M2 was the commonest, in the FAB classification, and AML showed higher predominance than ALL or CML. However, CML cases were found to be second commonest, this could be due to population bias, and its limitations in the study. Gender distribution showed a female preponderance of leukaemias as a whole in the study of the 56 cases. Males were of $48 \%$ and females $52 \%$. This again reflects the nature of swing in the population, though generally it is commoner in males. ${ }^{16}$ AML had a higher female preponderance of $58 \%$, against $42 \%$ in males, and it showed the same pattern in CML and CLL too, whereas ALL had more males showing $67 \%$ and females $33 \%$. Age distribution clearly shows ALL, predominantly in the children and early adolescence group, and ranges to about $92 \%$ of the cases, followed by AML with $42 \%$. CML was more common, in the 21 to 40 age group, and CLL had 33\% in the above 40 age group. Haemoglobin values were less than 6 gm $\%$ in $83 \%$ of ALL cases, and $71 \%$ in AML cases. $35 \%$ of CML cases, and $34 \%$ of CLL cases, had less than 6 gm $\%$, this clearly indicates, severe anaemia as a co-existing disorder, in cases of acute leukaemia. Total count values, were seen in high ranges in CML, with more than $100,000 / \mu$, in $58 \%$ of cases, and as much as $29 \%$ of them had more than 200 , $000 / \mu \mathrm{l}$, followed by AML, which had $46 \%$ of cases up to 50 , $000 / \mu \mathrm{l}$, and $25 \%$ more than that. ALL had $33 \%$ up to 50 , $000 / \mu \mathrm{l}$, and $25 \%$ in more than that. CLL had $67 \%$ of cases up to $11,000 / \mu \mathrm{l}$, and $33 \%$ less than $4000 / \mu$ l. This signifies that elevated counts will have less mature cells, and more of the immature variety. Leucopenia is an uncommon feature.1,6 Platelet counts in general are lower in acute leukaemias, and normal to higher or rarely lower in Chronic leukaemias. This was interpreted in the study, and ALL had 75\% cases with lesser values below 50,000/cumm, and AML had 71\% cases, below that level. CML had normal to higher values of more than $150,000 /$ cumm in $76 \%$ of their cases. CLL had more than $66 \%$ of their cases with more than $100,000 /$ cumm. This signifies that acute leukaemias, end up with less production of platelets, with decreased survival, causing thrombocytopenia. CML, usually has normal ranges in the chronic phase, but in the blast phase, they fall below the normal range just like in the acute cases. A thrombocytopenic picture in CML, always signals that an accelerated phase has started its process, leading to blast crisis. ${ }^{1}$

ANOVA analysis showed the $\mathrm{p}$ value to be statistically significant across the group of means of the laboratory values, in the haematological parameters. A clear picture of the haematological values in assessing the Total count, Platelet count and Haemoglobin is essential in the diagnostic aid of leukaemias. Various clinical presentations are seen in leukaemias, assessment of splenomegaly, hepatomegaly and lymphadenopathy, were taken into account in this study. Splenomegaly was the commonest feature seen in 21 cases, followed by hepatomegaly in 16 cases, and 7 cases had lymphadenopathy. One particular feature seen here was a lesser platelet count, a lower haemoglobin value, and a total count less than $50.000 / \mu \mathrm{l}$, in cases which had splenomegaly. There were no statistically significant differences, between the haematological value group means and the clinical features, as obtained by one-way ANOVA. Varying nature of clinical features were seen. CML invariably had splenomegaly in all their cases; and hepatomegaly was randomly seen in AML, as well as CML and ALL. CLL cases, all had lymphadenopathy. One case of AML M3 had disseminated 
intravascular coagulopathy, and one other case of CML in chronic phase, had visual disturbances. It is important to note that, in this study, the resources were limited, and costeffective measures had to be undertaken for the diagnosis. In a country like ours, where sophisticated laboratories having flow cytometric analysis for immunophenotyping, are limited in number, are a costly affair. Hence, here a select few cases, were taken to undergo Flow cytometric analysis. Six cases were taken into account. The main purpose was to see their concordance, with cytochemistry. 4 cases were concordant with the flow cytometric analysis, one ALL, one CML, and two AML cases were found to be concordant, with cytochemical findings, the other two ALL cases required a bone marrow aspirate, and secondary markers for the lineage identity, which as per our study was out of our limitations. $67 \%$ were concordant, and effective in diagnosing the cases in our study. Flow analysis uses a viable single cell suspension for the method, this consideration is important to note that haemodiluting effects can alter the analytical process, and can result in differences in results. Quality control and maintenance of equipment is highly essential, which should be scrupulously followed. By and large, a practical method, in our setting would be to do a basic peripheral blood smear with routine stains, and with cytochemistry and morphology, a diagnosis can be made. In case of ambiguity or lineage specific identification, for the follow up of therapy and prognosis, flow cytometric analysis and cytogenetics would be of immense help.

Leukaemias are a heterogenous group of disorders, having varied clinical, morphological, molecular cytogenetic characteristics, and have prognostic and therapeutic implications on identifying them correctly. In our study, predominance of myeloid neoplasms was found, and AML was the commonest type noted as per the statistical data. ALL was more common in the childhood category, and AML was more common in the adults' group, closely followed by CML. The gender distribution showed a slight raise in female preponderance as a whole, but Male predominance was seen in ALL type, with AML and CML having a slight female preponderance. Anaemia, as determined by haemoglobin values, was more severe in acute leukaemias, especially in ALL and AML, whereas it was mild to moderate in the chronic types. Leucocytosis was more in CML, and AML, as well as in ALL, than in CLL, depicting the clonal proliferation of cells. Thrombocytopenia was more in acute leukaemias, than in the chronic types, affirming the criteria for evaluation. Clinical features like splenomegaly were commonly present in CML; hepatomegaly was evenly distributed; lymphadenopathy was seen mostly in CLL. Cytochemical stains used were profoundly positive, in almost all cases, except in one case of chronic neutrophilic leukaemia. Acute leukaemias were well studied, with the stains, SBB and PAS, and accurately classified as per FAB classification.

\section{CONCLUSIONS}

A leukaemia diagnosis protocol is the need of the hour considering the economics involved. In a setting where there is a lack of facilities for flow cytometry, as in majority of centres in the developing countries, morphology combined with cytochemistry, still serves as the best means in diagnosing leukaemia cases.
Current therapeutics and prognostic factors rely more on flow cytometry and cytogenetics, and the WHO has classified leukaemias on its basis. This has prompted a new beginning in identification of the types and morphology. Hence a simpler adaptive format, with cost effective means can be devised in countries, where there are very few or no facilities.

\section{REFERENCES}

[1] Kuashansky K, Lichtman MA, Prchal JT, et al. Williams Hematology. 9th edn. New York: McGraw-Hill 2016: p. 35-7, 1275- 87, 1373-93, 1437-47, 1467-73, 1505-13, 1527-31.

[2] Hsi ED, Goldblum JR. Hematopathology, a volume in the series. Foundations of diagnostic pathology. 2nd edn. Philadelphia: Elsevier/ Churchill Livingstone 2006: p. 367-74, 397-429, 433-44, 455-89.

[3] Jaffe ES, Harris NL, Vardiman JW, et al. Hematopathology. $1^{\text {st }}$ edn. St. Louis: Elsevier Saunders 2010: p. 46-54, 672-96, 703-15.

[4] Tkachuk DC, Hirschmann JV. Wintrobe's Atlas of clinical hematology. $1^{\text {st }}$ edn. Philadelphia: Wolter Kluwer Lippincott Williams \& Wilkins 2007: p. 48-93, 105-6, 114-5, 212-7.

[5] McKenna RW. Beckman Conference. Multifaceted approach to the diagnosis and classification of acute leukaemias. Clinical Chemistry 2000;46(8 Pt 2):12529.

[6] Bain BJ, Bates I, Laffan MA, et al. Dacie and Lewis Practical Hematology. 11 th edn. Beijing: Churchill Livingstone 2012: p. 94-6, 339-50, 353-69.

[7] Deghady AAM, Mansour AR, Elfahham BAAAE. The value of cytochemical stains in the diagnosis of acute leukaemia. Research and Health Sciences 2016;2(5):17.

[8] Beckman H, Neth R, Gaedicke G, et al. Cytology and cytochemistry of the leukemic cell. University of Hamburg, German. 1972.

[9] Bennett JM, Dutcher TF. The cytochemistry of acute leukaemia: observations on glycogen and neutral fat in bone marrow aspirates. Blood 1969;33(2):341-7.

[10] Mhawech P, Buffone GJ, Khan SP, et al. Cytochemical staining and flow cytometry methods applied to the diagnosis of acute leukaemia in the pediatric population: an assessment of relative usefulness. J Pediatr Hematol Oncol 2001;23(2):89-92.

[11] Snower DP, Smith BR, Munz UJ, et al. Re-evaluation of the periodic acid Schiff stain in acute leukaemia with immunophenotypic analyses. Arch Pathol Lab Med 1991;115(4):346-50.

[12] Berlukar S, Mantravadi H, Manohar C, et al. Correlation of morphologic and cytochemical diagnosis with flowcytometric analysis in acute leukaemia. J Can Res Ther 2013;9(1):71-9.

[13] Qadir M, Barcos M, Stewart CC, et al. Routine immunophenotyping in acute leukaemia: role in lineage assignment and reassignment. Cytometry B Clin Cytom 2006;70(5):329-34. 


\section{Jemds.com}

[14] Venkateswaran SP, Jojo A, Vidhyadharan G, et al. A clinicopathological correlation of acute leukaemias in relation to immunophenotyping and cytogenetics. Int J of Collaborative Research on Int Med and Public Health 2012;4(10):1713-37.

[15] Peters JM, Ansari MQ. Multiparameter flow cytometry in the diagnosis and management of acute leukaemia. Arch Pathol Lab Med 2011;135(1):44-54.

\section{Original Research Article}

[16] Salkar AB, Patrikar A, Bothale $K$, et al. Clinicohaematological evaluation of leukaemias in a tertiary care hospital. IOSR-JDMS 2014;13(12):126-34. 